\title{
Covid-19 Pandemi Sürecine Yönelik Kamu Spotlarının Etkinliği Üzerine Bir Araştırma
}

DOI: $10.26466 /$ opus. 810640

*

\author{
Engin Çelebi* - Seyfi Özgüzel ** \\ * Doç. Dr., Çukurova Üniversitesi, A.S. Sağlık Hizmetleri MYO., Adana/Türkiye \\ E-Posta: engincelebi@cu.edu.tr \\ ORCID: $\quad 0000-0001-5791-8080$ \\ ** Prof. Dr., Çukurova Üniversitesi, İletişim Fakültesi, İletişim Bilimleri Böl. Adana/Türkiye \\ E-Posta: sozguzel@cu.edu.tr \\ ORCID: $\underline{0000-0003-4859-0479}$
}

\section{Öz}

Bu çalışmanın amacı salgın döneminde kamusal duyarlılı̆̆ın sağlanmasına ve kamusal davranışların etkilenmesine yönelik yapılan kamu spotlarında kullanılan iletişim stratejilerinin etkinliğinin incelemesi ve dijital ortamlardaki söylemlerin ele alınması, böylece yaşam dengesinin stratejik öneminin iletişim perspektifi ve motivasyonu açısından ortaya çıkartılmasıdır. Bu amaca yönelik olarak İletişim Fakültesinde öğrenim gören 116 kişi üzerinde açık uçlu sorular ve anket tekniğgi ile bir araştırma yapılmıştır. Araştırma bulgularına göre kamu spotlarını: koruyucu davranışlara odaklanmak, olumlu bilgi iletmek, zihinlerde oluşan kaygı ve belirsizlikleri yok etmek için düzeltici eylem rolü üstlenmek ve toplumun salgın döneminde olumsuzluklarla psikolojik olarak başa çıkmak açısından olumlu bir motivasyon kaynağı olarak görüldü̈̆̈̈̈ bulgusuna ulaşılmıştır. Araştırma sonucunda özelliklede iletişim stratejileri tasarlanırken empati yapılmasının ve duyguların hesaba katılmasının önemi ortaya çıkartılmıştır. Diğer yandan dijital ortamlarda toplumun iletişimsel davranışlara nasıl dâhil oldukları, kamusal davranışları farklı şekillerde nasıl etkilediği ve dijital ortamlarda iletişimsel uygulamaların gücü ve etkisi araştırılmıştır. Araştırma bulgularına göre dijital ortamlarda genellikle halk sağlı̆̆ına yönelik olumsuz içerikte paylaşımlar yapılmaktadır. Dijital ortamlarda bilgilerin manipüle edilebilmesi, verimsiz tartışmalar ve ilgisiz konular ile verilen tepkilerin öfke, hayal kırıklı̆̆l, stres, korku, güvensizlik, alaycılık vb. çok sayıda olumsuz duygular yaratabilme potansiyeline sahip olduğu bulgusuna ulaşılmıştır.

Anahtar Kelimeler: Pandemi, Covid19, Kamu Spotları, Etkili Iletişim, Dijital Ortamlar 


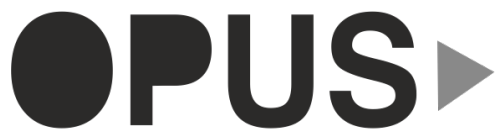

Uluslararası Toplum Araştırmaları Dergisi International Journal of Society Researches
E-ISSN : 2528-9535

YIl Year: 11

Cilt Volume: 17

Sayı Issue :Pandemi Özel Sayısı

Nisan April 2021

Makalenin Geliş Tarihi Received Date: 16/10/2020

Makalenin Kabul Tarihi Accepted Date: 02/01/2021

\title{
A Research on The Effectiveness of Public Spots oor Covid-19 Pandemic Process
}

*

\begin{abstract}
This study examines the effectiveness of the communication strategies used in public media spots and addresses the discourses in digital media to ensure public sensitivity and influence public behaviors during the pandemic period and reveal the strategic importance of life balance in terms of communication perspective and motivation. For this purpose, research was conducted with open-ended questions and survey technique on 116 students studying at the Communication faculty. According to the research findings, it was found that public spots were seen as a positive motivation source in terms of focusing on protective behaviors, conveying positive information, taking corrective action role in eliminating anxiety and coping psychologically with the negativities during the pandemic period of the society. As a result of the research, the importance of empathy and emotion are taken into account while designing communication strategies. On the other hand, the power and effect of communicative applications in digital media and how society is involved in digital media's communicative behavior and how it affects public behavior in different ways are investigated. According to the findings, it is generally in a digital environment, harmful content for public health shared. The ability to manipulate information in digital environments, inefficient discussions, irrelevant issues, and responses to anger, frustration, stress, fear, insecurity, sarcasm, etc., is possible. It has been found that it has the potential to create many negative emotions.
\end{abstract}

Keywords: Epidemic, Covid19, Public Spots, Effective Communication, Digital Environments 


\section{Giriş}

Toplum sağlığının tehdit edilmesi ile ortaya çıkan sağlık riskine yönelik olarak kamu spotları aracılığıyla sağlık kurallarına uyumun nasıl algılanacağı önemli bir araştırma alanı haline gelmiştir. Bu çalışmanın amacı ise iletişim tekniklerinin etkisini belirlemek ve bu etkinin duygusal ve davranışsal değişikliklerle nasıl ilişkili olduğunu ortaya çkartmaktır. Bu amaca yönelik olarak sağlık kurallarına yönelik tutumlarda kamu spotlarının aracı rolünün test edilmesi amaçlanmaktadır.

İletişim kampanyalarında etkili bir mesaj stratejisinin kullanılması harcanan zaman ve çabanın daha verimli olmasına katkı sağlayabilir. Bu ise toplum sağlığını tehditlere karşı motive edici faktörleri ele alan disiplinli bir iletişim stratejisinin uygulanmasını gerektirir. Eğer sorunun başarılı bir şekilde çözümlenmesi, kalıcı çözüm süreçleri ve yöntemleri üretilmesi ve davranışsal süreçte olumsuz tekrarların önlenmesi isteniliyorsa uygulamalarda motivasyonel faktörlerin itici güçleri tanınmalıdır.

Sadece iletişimsel bir yöntem olarak değil aynı zamanda kapsamlı bir anlayışla ve toplumun ruh halini algılama kapasitesiyle birlikte iletişimsel uygulamalar kamu spotları aracılığıly toplumsal güvenin inşa edilmesini sağlayabilir. Halkla iletişimin etkin bir şekilde yönetilebilmesi için öncelikle bilgi ve duygunun gerçekçi bir şekilde ifade edilmesi, sorumlu ve hesap verilebilir bir şekilde hareket edilmesi ve bunların kamuoyuna aktarılması gerekmektedir.

Salgın döneminde kamu spotlarının etkinliği, dijital ortamlardaki tartışmalar, toplumsal algı ve sosyal uyum arasındaki ilişkilerin ortaya çıkartılmasına yönelik yapılan bu çalışmadan elde edilen bulgular ile literatürdeki boşluğun doldurulması ve teorik ve pragmatik çıarımlar elde edilmesi amaçlanmaktadır.

\section{Salgın (Afet) Döneminde Risk İletişimi ve Etkili Stratejik İletişim Tekniklerinin Önemi}

Stratejik iletişim farklı disiplinlerden gelen teorik yaklaşımları bütünleştirmektedir. İletişim stratejilerinin üretilmesi ve sunulması konusundaki etkililik, yeterlilik ve bunların inanç, tutum ve duygulara yönelik etkinliği oldukça önemlidir. Olumlu bir tutumsal tepki yaratmak için önemli bir motivasyon 
kaynağı olan etkili iletişim stratejileri salgın döneminde toplum sağlığını korumak için bir araç olarak kullanılmaktadır.

Salgın döneminde toplum sağlığı büyük bir tehditle karşı karşıyayken bu süreç iletişim teorisi ve pratiğinin öneminin ortaya çıkartılmasına katkıda bulunmakta ve etkili iletişim stratejilerinin dinamiklerine işık tutmaktadır. Salgın dönemi iletişimsel çabaların başarısını veya başarısızlığını değerlendirmeye, davranışsal uyum sürecinde iletişimsel uygulamaların oynadı̆̆ı rolü ortaya çıkartmaya ve uygulayıcıları alternatif iletişimsel stratejiler üzerinde düşünmeye yöneltmiştir. İletişimsel uygulamalar toplumun salgın döneminde kendisini nasıl koruyacağı konusunda tavsiyeler vermesi ve bu süreçle psikolojik olarak nasıl başa çıkılabileceği konusunda yardımcı olunması bilgileri üzerine yoğunlaşmaktadır. Bu yüzden psikolojik yönleri de içeren, kaygı ve belirsizliği azaltan bir iletişim stratejisinin uygulanması beklenmektedir. Gudykunst'a (2014, s.23) göre belirsizlik bilişsel, kaygı ise duygusaldır. Yazar'a göre belirsizlik tutum, duygu, inanç, değer ve davranışları tahmin etme konusundaki yetersizliktir. Belirsizlik arttıkça insanların davranışlarındaki tutarlılık azalmakta ve tedirginlik oluşmakta/artmaktadır. Kaygı ise huzursuz, tedirgin, gergin ve endişeli olma durumuyla ilgilidir. Hofstede'ye (2011, s.8) göre belirsizlikten kaçınma geleceğe yönelik kaygıların derecesi ile ilgilidir. Kaygı ve belirsizliğin üstünden gelmek ve olumsuzluklarla psikolojik olarak başa çıkmak açısından ise kamuoyuna ne yapılacağı ve nasıl davranılacağ1 konusunda bilgi iletmek önemlidir. Çünkü Choi ve Lin (2009, s.204) bir kriz durumu esnasında halkın genel duygularını tespit etmiş ve bu duyguların öfke, endişe, şaşkınlık, korku ve karışıklık gibi olumsuz duygularla yüksek derecede ilişkili olduğu bulgusuna ulaşmıştır.

Psikolojik ve fiziksel yönden tehdit algısı olarak değerlendirilen büyük bir afet veya olay sürecinde psikolojik olarak duygusal bir sıkıntı, kontrol kaybı, çaresizlik, kaygı ve stres hissedilebilir, ne yapılacağı ve nasıl davranılacağı konusunda bilgi eksikliği olabilir. Bu faktörler depresyon gibi uzun vadeli olumsuz duygusal sonuçlar doğurabilir. Çözüm olarak ise özel rehberlik uygulamalarına yönelik olarak kamu kurum ve kuruluşlarının önerilerine bakmaya ihtiyaç duyulabilir. Bu nedenle açık ve net bilgilere dayanan önerilere dair mesajlar kaygı ve stresin azaltılması, güven oluşturulması ve yapıcı eylemler için önkoşuldur. Bunun için ise öncelikle iletişim stratejileri bağlaminda duygusal kaygıların ele alınması gerekmektedir. 
"Afet" terimi ile "kriz" terimi sik sık birbirinin yerine kullanılsa da krizlerin "örgütsel temelli" ve afetlerin "toplum temelli" olaylar olduğu konusunda önemli bir ayrım vardır (Seeger vd., 1998). Coombs $(2014,2019)$ krizi örgütsel kriz ve afet (felaket) olarak ikiye ayırmaktadır. Yazar'a göre, afetler: sistem rutinlerini bozan, değerleri ve sosyal hedefleri tehlikeye atmamak için başa çıkma prosedürleri gerektiren, birçok kamu kurumunun yanıt vermesi gereken, ani gelişen, büyük ölçekli ve öngörülemeyen olaylardır. Benoit'e göre (1995) kriz iletişimi ya da kriz durumuna kurumsal tepki bir kriz yönetim planının başarısına katkı sağlamaktadır.

Ulusal Bilim ve Teknoloji Konseyi (NSTC, 2005) bir afeti "bir toplumun işleyişinde ciddi aksamalar meydana getiren, toplumun kendi kaynaklarını kullanma becerisini engelleyen, yaygın bir şekilde beşeri, maddi, ekonomik veya çevresel kayıplara neden olan bir olay" şeklinde tanımlamaktadır. Risk iletişimi ise bireylerin afet öncesinde, esnasında ve sonrasındaki risk bilgisine, tutum ve davranışlarına odaklanır (Cheng ve Lee, 2019, s.2). Bir afet sırasında risk iletişimi, insanları koruyucu önlemler almaya teşvik etmede önemli bir rol oynar. Risk iletişiminin bazen beklenildiği gibi etkili olamamasının nedenleri arasında: tehlikelerin karmaşıklı̆gı, insanların bu tarz durumlardaki deneyim eksikliği, bu duruma uyum sağlanamaması ve ilgili bilgileri elde etmek için başkalarına güvenme ihtiyacı bulunmaktadır (Paton, 2008).

Risk iletişimi üzerine yapılan akademik çalışmalar psikoloji disiplininden evrimleşmiştir ve temel olarak bireylerin bilinen risklere yönelik bilgi, tutum ve davranışlarını etkilemek için ikna edici mesajların nasıl tasarlanacağı ve sunulacağı üzerine odaklanmıştır (Witte, 1995, s.249).

Dünya Sağlık Örgütüne (WHO) göre halk sağlığına yönelik acil durumlar için risk iletişimi: bilinçli karar vermeyi, olumlu davranış değişikliğini ve güvenin sürdürülmesini teşvik etmek için ciddi bir halk sağlığı olayına hazırlanılmasını, müdahale ve toparlanma aşamaları boyunca gerekli olan iletişim kapasitelerini içermektedir. Risk iletişimi, öncelikle hastalık riskleri ve bu riskleri azaltmak için davranışların nasıl değiştirileceğine dair talimatlar gibi sağlık riskleri ve olayları hakkında kamuoyuna bilgi verilmesi olarak görülmektedir. Uygulama alanları ise 21. yüzyılda yeni iletişim ve medya teknolojileri ile birlikte genişlemiştir.

Afet iletişimi hükümetler, acil durum yönetim organizasyonları ve afet müdahalecileri tarafindan kamuya yayılan bilgiler ile medya ve halk tarafından oluşturulan ve paylaşılan afet bilgilerini kapsamaktadır (Fraustino vd., 
2012, s.4). Büyük afetler sadece bu durumdan etkilenenler arasında değil sezgisel olarak bu olumsuz durumdan etkilenme potansiyeline sahip olabilecek kişiler arasında da olumsuz psikososyal etkiler yaratabilme potansiyeline sahiptir. Bilgi eksikliği, ne yapılacağı konusunda rehberlik eksikliği, korku ve endişe gibi duygusal sıkıntıları kabul etmek vb. nedenler psikososyal açıdan uzun vadeli olumsuz duygulara neden olabilecek bir etkiye sahiptir (Marynissen \& Lauder, 2020, s.176). Bu sorunların çözümüne yönelik olarak oluşturulacak etkili iletişimsel uygulamalar ise bu sorunlarla başa çıkmak ve toplumsal güveni sağlamak için etkili bir yöntem olarak görülebilir.

Risk ve kriz iletişimi afet iletişimi ile yakından ilişkilidir. Örneğin, uyarı mesajlarının nasıl tasarlanacağını ve dağıtılacağını bilmek risk iletişiminin önemli bir bileşenidir (Rodriǵuez vd., 2007). Risk iletişimi bir afet sırasında insanları koruyucu önlemler almaya teşvik etmede önemli bir rol oynar. Risk yönetiminin temel hedefi, doğal tehlikelere eğilimli alanlarda, insanları koruyucu önlemleri almaya teşvik ederek riski azaltmaktır. Acil durum yönetimi kuruluşlarının çabalarına rağmen koruyucu önlemlerin sürekli olarak benimsenmesini sağlamak zor olabilmektedir. Tehlikelerin karmaşıklığı, insanların bu tarz durumlardaki deneyim eksikliği ve risk iletişimi sürecinde ilgili bilgileri elde etmek için başkalarına güvenme ihtiyacı ve seviyesi risk yönetiminin başarısında önemli faktörlerdir. Tehlikelere aşinalık ve hazırlıklı olma, bunlarla ilgili bilgilerin mevcudiyeti, koruyucu önlemlerin alınmasına ilişkin kararlara yönelik duyulan güvenin yapısal özellikleri arasındaki ilişkiler risk iletişiminin etkinliğinde önemli bir rol oynayabilmektedir (Paton, 2008).

Risk iletişiminde amaç risklere karşı bilinç ve farkındalık oluşturulması, önlem alınması ve risklerin neden olabileceği belirsizliklerin önüne geçebilmektir. Bu ise risk konusuyla ilgili bilgi edinmek ile mümkün olduğundan risk iletişiminin başarıya ulaşması için bilgi okuryazarlığı düzeyinin temel bir faktör olduğu söylenebilir. Diğer yandan, kamuoyunun ihtiyaç duyduğu bilgilerin aktarılmasının ötesinde, aktarılan bu bilgilerin nasıl yorumlandığı ya da anlaşıldığı önemli bir konudur (Turancı, 2018, s.191).

\section{Salgın Döneminde Dijital Ortamlarda İletişim}


Dijital çağda iletişim stratejilerinin etkinliği dijital ortamlarda bireyler arasındaki ilişkilerin bir fonksiyonudur. Dijital çağda oluşan yeni iletişim kanallarının toplumun sosyal davranışlarına yön verdiği söylenebilir. Dijital ortamlarda açık platformlar aracılı̆̆ıyla bireyler "pasif" bilgi alıcılardan "aktif" içerik üreticilerine dönüşmüştür. Dijital ortamlarda çok sayıda aktör vardır. $\mathrm{Bu}$ aktörler arasında bilgiyi analiz etmek, üretmek ve dağıtmak konusunda ve söylemsel alanda bir mücadele olabilmektedir. Dijital ortamlarda kullanıcılar tarafından salgın döneminde kimlerin veya hangi kuruluşların sorumluluk alması gerektiği, mevcut durumların nasıl hafifletilebileceği önerilebilmektedir. Dijital ortamlarda halk sağlığını önemseyen, halk sağlı̆̆ının bu durumdan nasıl etkilendiğini veya bu durumdan nasıl etkilenebileceğini ve korunabileceğini vurgulayan ve tavsiyeler içeren gönderiler sunulabilmektedir. Dijital ortamlarda yazılı ve görsel bilgiler aracılığıyla kullanıcılar kendi bakış açılarını çerçeveleyebilmekte, öfke, üzüntü veya kaygılarını ifade eden duygusal ifadeler paylaşabilmektedir. Bireyler ve sosyal gruplar arasındaki geleneksel medyanın gönderilerine yönelik olarak tartışmalı ve farklı bakış açıları oluşabilmekte ve anlaşmazlıklar yaşanabilmektedir. Çevrim içi tartışmalar bireysel veya grupsal hedefler dâhilinde yeni bir yön de kazanabilmektedir.

Halk genellikle bir olaydaki sorumlulukların ortaya çıkartılmasını sağlamak, bir sorunu çözme adımlarını tartışmak ve afetleri anlamlandırmak için sosyal medyada düşüncelerini ifade etmektedir (Stieglitz vd., 2018, s.13). Veil vd. (2011, s.119) dijital (sosyal) medyanın kamuoyunun riskler konusunda eğitilmesinde, kamu desteğinin teşvik edilmesinde ve açık diyalog için mekânlar yaratılmasında yararlı olduğunu ileri sürmüştür. Ayrıca, sosyal medyada duyguların ifade edilmesi halkın afetler sırasında yaşadıkları olumsuz duygularla başa çıkmasına yardımcı olabilmektedir (Jin vd. 2016, s.305).

Saglık iletişiminde sosyal medya kullanımını COVID-19 salgını üzerinden inceleyen Tanyıldızı (2020, s.107) Türkiye'de ve farklı Ülkelerde yapılmış olan bilimsel çalışmaların çoğunlukla sosyal medyada enformasyonun doğru olup olmaması, sosyal medyanın avantajları- dezavantajları, toplum üzerindeki etkileri ve bu bağlamda sosyal medyanın sağlık iletişimine katkısı üzerinde ele alındığı bulgusuna ulaşmıştır.

Zhao vd. (2019, s.387) yapmış oldukları araştırma sonucunda bir afet/felaket sonrasinda kamuoyunun sosyal medyayı kullanma motivasyonlarında farklı iletişim işlevlerini benimsediği bulgusuna ulaşmışlardır. Araştırmacılara göre bireyler sosyal medya ortamlarında bilgi paylaşımı, destek 
alışverişinde bulunma, düşüncelerini ifade etme ve bu durum ile duygusal olarak başa çıkma vb. nedenlerden dolayı sosyal medyayı kullanmaktadırlar. Ayrıca, sosyal medyada görüşlerin ifade edilmesi, halkın belirsiz ve kontrol edilemeyen afetleri anlamasına ve kendi kriz deneyimlerini oluşturmalarına yardımcı olmaktadır (Borah, 2011; Van Der Meer, 2016). Diğer yandan, Coombs'a (2014) göre sosyal medyanın artan popülaritesi nedeniyle, doğrusal bir planlama modeli benimsemek, katılımcllara nesnel hedefler olarak davranmak, kuruluşlar ve kamuoyu arasındaki bilgi iletimine odaklanmak oldukça zordur.

\section{Araştırma}

\section{Araştırma Sorularının Oluşturulması}

İletişim stratejileri oluştururken farklı hedef kitle gruplarına yönelik olarak farklı iletişim stratejileri kullanılması gerekebilmektedir. Salgın döneminde arzulanan uzun süreli sağlıklı bir anlayışın oluşturulabilmesi için ortak stratejik yaklaşıma yönelik olarak toplum üzerinde hangi ortak duyguların daha etkili olduğunu ve hangi unsurların olumsuz algilamalara neden olabileceğini anlamak için açık uçlu sorularla yanıt aranacak olan ilk iki araştırma sorusu şu şekilde oluşturulmuştur:

Araştırma Sorusu 1: Geleneksel ve sosyal medyada iletişim stratejilerinin etkisini arttırmaya yönelik olarak hangi ortak özellikler ön plana çıkmaktadır?

Araştırma Sorusu 2: Geleneksel ve sosyal medyada olumsuz algilamalara neden olabilecek iletişim stratejilerine yönelik olarak hangi ortak özellikler ön plana çıkmaktadır?

Üçüncü araştırma sorusunda kamu spotlarında verilen mesajlara duyulan güven ile Türkiye'deki sağlık kuruluşlarına olan güven duygularının karşılaştırılması amaçlanmıştır.

Araştırma Sorusu 3: Kamu spotlarında verilen mesajlara duyulan güven ile Türkiye'de ki sağlık kuruluşlarına duyulan güven arasında bir ilişki var mıdır?

İletişim stratejilerinin etkinliğine veya etkisizliğine dair algilamalar ile dijital ortamlarda olumlu/olumusuz söylemlerde bulunma, yorum yapma, 
beğenme ve paylaşma davranışları arasındaki ilişkiyi ortaya çıkartmak için dördüncü araştırma sorusu şu şekilde oluşturulmuştur;

Araştırma Sorusu 4: Kamu spotlarında kullanılan iletişim stratejilerinin etkinliği ile sosyal medya ortamlarındaki etkileşimler arasında nasıl bir ilişki vardır?

Araştırma kapsamında dijital ortamlardaki söylemler katılımcların kamusal çabaları öven ya da eleştiren her türlü ifadeyi içeren mesajlar ve tepkiler olarak belirlenecektir.

\section{Araştırmaya Dair Bilgiler}

Araştırma kapsamına dâhil edilenlerden salgın döneminde etkili ve olumsuz algılamalara neden olabileceği için etkisiz buldukları kamu spotlarını tanımlamaları ve tüm detayları boş bir metin kutusuna yazmaları istenilmiştir. Böylece kamu spotlarında kullanılan iletişim stratejilerinin tanımlanması ve kategorize edilmesi amaçlanmıştır. Sonrasında ise katılımcılardan dijital ortamlardaki tutum ve davranışlarını ölçen bir anketi yanıtlamaları istenilmiştir.

Anket ölçeğinde toplam 13 madde kullanılmıştır. 5'li likert ölçeğe göre oluşturulan (1- Kesinlikle katıllyorum, 5- Kesinlikle katılmıyorum) anket ölçeğinde yer alan maddelerden bazıları kontrol amaçlı olarak birbirleriyle ters orantılı verilmiştir. Anket maddelerinde kamu spotlarında kullanılan iletişim stratejilerinin etkinliğini ölçmek için 5 madde (Örnek: Kamu spotlarında verilen bilgiler sayesinde kendimi rahat ve güvende hissediyordum) kullanilmıştır. Kamu kuruluşlarına olan güven unsurunu ölçmek için 5 madde (Örnek: Salgından sonra kamu kuruluşlarına olan güvenim güçlendi) ve dijital ortamlardaki paylaşımları ölçmek için 3 madde kullanılmıştır (Örnek: Kamu spotlarına yönelik sosyal medyada olumlu düşünceler yazdım/olumlu durumları sosyal medyada beğendim/paylaştım veya yorumladım). Ölçekte yer alan maddelerin iç tutarlılığ 1 bir ön çalışma ile 40 kişi üzerinde test edilmiştir ve bu ön çalışmada anket maddelerinin Cronbach's Alpha değeri .866 olarak ölçülmüş̧ür. Bu değer yüksek bulunduğu için anket uygulamasına devam edilmiştir. 116 kişiye uygulanan araştırma anketinde yer alan maddelerin iç tutarlılığının Cronbach's Alpha değeri ise .880 olarak ölçülmüştür. Anket soruları oluşturulurken benzer çalışmalarda (Çelebi, 2020a; Schultz vd. 2017) kullanılan ölçeklerden yararlanılmıştır. Toplam 116 kişiye yapılan anket 
uygulamasında veriler katılımclardan gönüllülük esasına göre dijital ortamda toplanmıştır ve verilerin toplanması yaklaşık 1 ay (Ağustos 2020) sürmüştür. Araştırmanın örneklemini 18-30 yaş aralığında olan ve İletişim fakültesinde eğitim gören kişiler oluşturmaktadır. Araştırmaya katılanların \% 46.6'sını (n =54) kadınlar, \% 53.4'ünü (n=62) ise erkekler oluşturmuştur. Araştırma için Girişimsel Olmayan Klinik Araştırmalar Etik Kurulundan etik kurul raporu alınmıştır (Yıl: 2020, Toplantı Sayısı: 102, Karar No: 21).

\section{Araştırma Bulguları}

İlk araştırma sorusu olarak geleneksel ve sosyal medyada iletişim stratejilerinin etkisini arttırmaya yönelik olarak hangi ortak özelliklerin ön plana çiktığını belirlemek için katılımcıların anket formunda yer alan boş mesaj kutusuna yazmış oldukları metinler analiz edilmiş ve ortak özellikler belirlenmiştir. Araştırma bulgularına göre kamu spotlarının etkinliği için yeterli bilgi verilmesi ve bunların kısaca ifade edilmesi, basit bir dille anlatılması, açk, tutarlı ve inanılır olması öncelikli özelliklerdir. Araştırmanın örneklemini İletişim bilimleri alanında Üniversite eğitimi alan ve eğitim seviyesi yüksek olan bireyler oluşturduğu için katılımcılar kamu spotlarında verilen bilgilerin sosyodemografik farklılıklara göre kolayca anlaşılabilmesinin önemini vurgulamışlardır. Ayrıca kamu kurumlarına ve devlete olan bilişsel ve duygusal güven kamu spotlarında verilen mesajlara olan güveni de etkilemektedir. Çünkü araştırma bulgularına göre katılımcların \% 79'u sağlık kuruluşlarına ve Devlete olan güven duygusunun önemine dikkat çekmişlerdir. Bu yüzden mesajların etkinliğini arttırmak için olumlu tutumları ve inandırıcılığı etkileyen güven duygusunu neyin arttırdığının veya azalttı̆ının ortaya çıkartılması gerekmektedir. Empati kurulması ve tepkilerin dikkate alınması gibi yaklaşımlar ise sosyal medya ortamlarına özgü bir özellik olarak belirlenmiştir. Önlemlere yönelik tavsiyelere ek olarak katılımcıların sosyal medyada salgın durumunun nasıl ortaya çıktığıyla ilgili iletilere de ilgi duyduğu bulgusuna ulaşılmıştır. Katılımcılar iletişim stratejilerinin etkinliğine ve davranışsal niyetlere göre farklı tutumlarda göstermişlerdir. Katılımcların tamamına yakını sosyal medya ortamlarında: sorumluluk alınması, salgının nasıl ortaya çıktığı, kontrol altına alınıp alınamayacağı, kimlerin sorumlu ve suçlu olduğu, hangi davranışı sergilemesi gerektiği, ne yapmalı (ne yapmamalı) ya da nasıl davranmalı (veya davranmamalı) ile ilgili konularda fikir ve destek 
alışverişinde bulunduklarını beyan etmişlerdir. Araştırma verilerine göre iletişim stratejilerinin etkinliği/etkisizliği kamu spotlarında verilen tavsiyelere uymada ve bilinç oluşturmada önemli bir göstergedir. Ayrıca katılımcıların $\%$ 81'i etkili iletişim stratejileri tasarlanırken empati kurulmasını ve mantıksal olduğu kadar duygusal desteğe yönelik ifadeler kullanılmasını etkili bulmuştur.

İkinci araştırma sorusu olarak olumsuz algilamalara neden olabilecek etkisiz iletişim stratejilerini belirlemeye yönelik ise yine katılımıların anket formunda yer alan boş mesaj kutusuna yazmış oldukları metinler analiz edilmiş ve ortak özellikler ortaya çıkartılmıştır. Katılımcıların \% 57'si etkili bulmadıkları iletişim tekniklerinin özelliklerini belirtirken kamu spotlarında verilen mesajlarla sadece iyi niyet gösterilmesini, kamuoyunun bilgi alma ihtiyacının karşılanmasının ötesine geçilmemesini ve sorumluluk alınmamasını ön plana çlkarmıştır. Böylesi bir durum kamu kurum ve kuruluşlarının, yani devletin, meşruiyetinin sorgulanmasına sebebiyet verebilmektedir. Dijital ortamlarda ise $\% 42$ oranında halk sağlığını olumsuz içerikte paylaşımlar yapıldığı bulgusuna ulaşılmıştır. Dijital ortamlarda tehlikeli, tehdit edici, göz korkutucu, zararl, riskli ifadeler, endişe yaratıcı ve arttırıcı bilgiler iletilmekte ve paylaşımlar yapılmakta ve belirsizlik algısı yaratılmaktadır. Dijital ortamlarda genellikle neler olup bittiğine yönelik duygusal (bilişsel değil) ve endişe verici ifadelere sıklıkla rastlanıldığı ve bunların ise anında olumsuz etkiye neden olabileceği belirtilmiştir. Araştırmanın örneklemini sosyal medyayı düzenli ve etkin bir şekilde kullanan Üniversite öğrencileri oluşturduğu için bu bulgu kamuoyunu, özellikle de gençleri, sürece dâhil etmenin önemini ortaya çıkartmaktadır. Bu yüzden salgın dönemini atlatmak için neler yapıldığı, nasıl çalışıldığı ve benzer durumların yinelenmemesi için neler yapılması gerektiği bilgisinin şeffaf bir şekilde verilmesi sosyal medyadaki asılsız dedikoduların önlenmesi için gereklidir.

Araştırma sorusu 3'e, yani kamu spotlarında verilen mesajlara duyulan güven ile Türkiye'de ki sağlık kuruluşlarına duyulan güven arasındaki ilişkiye, yanıt aramak için kamu spotlarında verilen mesajlara güvenenlerin ve güvenmeyenlerin ortalamaları ile Türkiye' de ki sağlık kuruluşlarına duyulan güven duygularının ortalamaları karşılaştırılmıştır. Tablo 1'de gösterildiği üzere kamu spotlarında verilen mesajlara güvenmeyenlerin Türkiye'de ki sağlık kuruluşlarına duydukları güven duygularının ortalamaları düşük bir sonuç (2.37/5.00) vermiştir. Kamu spotlarını etkili bulan ve verilen mesajlara 
güvenenlerin ise Türkiye' de ki sağlık kuruluşlarına duymuş oldukları güven duyguları yüksek bir sonuç (3.88/5.00) vermiştir. Bu oranlara bakıldığında, Türkiye'de bulunan sağlık kuruluşlarına güven duymayan bireylerin benzer şekilde kamu spotlarında verilen mesajlara da güvenmedikleri görülmektedir. Öte yandan, Türkiye' de bulunan sağlık kuruluşlarına güvenen bireylerin ise benzer şekilde kamu spotlarında verilen mesajlara da güvendikleri gözlenmektedir. Bu nedenle sağlık kuruluşlarına karşı güven duygusunu güçlendirmenin aynı zamanda kamu spotlarının etkinliğine yönelik toplumsal güveni de güçlendirmek anlamına gelebileceği söylenebilir. Çünkü, Tek yönlü Anova testi sonucuna göre \% 95 güvenle iki grubun ortalamaları arasindaki fark anlamlı bulunmuştur $(F=21,294 \mathrm{p}<0.05)$.

Tablo 1. Kamu Spotlarnda Verilen Mesajlarn Etkinliği İle Türkiye’de ki Sağlık Kuruluşlarna Duyulan Güven Duygularnın Ortalamalar

\begin{tabular}{llll}
\hline Sağlık Kuruluşlarına Duyulan Güven & Sayı & Ortalama & Std. Sap. \\
\hline Kamu Spotlarını Etkisiz Bulanlar & 47 & 2,3768 & 0,7873 \\
\hline Kamu Spotlarını Etkili Bulanlar & 69 & 3,8841 & 0,8195 \\
\hline
\end{tabular}

Araştırma bulgularına göre kamu spotlarında verilen mesajlara duyulan güven ile Türkiye' de ki sağlık kuruluşlarına duyulan güven arasında .745 korelasyon katsayısı ile oldukça yüksek bir ilişki bulunmuştur.

Kamu spotlarında kullanılan iletişim stratejilerinin etkinliği ile sosyal medya ortamlarındaki etkileşimler arasındaki ilişkiyi ölçmeyi amaçlayan araştırma sorusu 4'e yanıt aramak için istatistiksel veriler analiz edilmiştir. Tablo 2'de gösterildiği üzere kamu kuruluşlarına ve kamu spotlarında verilen iletilere güvenenlerin oranı (69 kişi, \%59.5 ) ve bu katılımcıların sosyal medyada olumlu söylemler yazma/paylaşma/beğenme/yorumlama oranları oldukça yüksek bulunurken (3.89/5.00) olumsuz söylemlere yönelik ortalamaları düşük bir oran (2.35/5.00) vermiştir. \% 95 güven aralığında yapılan tek yönlü Anova testi sonucuna göre aralarındaki fark anlamlı bulunmuştur $(\mathrm{F}=$ $31,596 \mathrm{p}<0.05)$.

Tablo 2. Kamu Spotlarnı Etkili Bulan Katılımcılarn Sosyal Medya Reaksiyonlar

\begin{tabular}{lllc}
\hline Sosyal Medya Reaksiyonları & Sayı & Ortalama & Std. Sap. \\
\hline Olumlu Söylemlerde Bulunma & 69 & 3,8987 & 1,15019 \\
\hline Olumsuz Söylemlerde Bulunma & 69 & 2,3544 & 1,50246 \\
\hline
\end{tabular}

Tablo 3'de gösterildiği üzere kamu kuruluşlarına ve kamu spotlarında verilen iletilere güvenmeyen katılımclların (47 kişi, \% 40.5) sosyal medyada 
olumlu söylemlerde bulunma oranları düşük bulunurken (2.21/5.00) olumsuz söylemlerde bulunma oranları oldukça yüksek (4.13/5.00) bulunmuştur.

Tablo 3. Kamu Spotlarnı Etkisiz Bulan Katılımcılarn Sosyal Medya Reaksiyonlarn

\begin{tabular}{llll}
\hline Sosyal Medya Reaksiyonları & Sayı & Ortalama & Std. Sap. \\
\hline Olumlu Söylemlerde Bulunma & 47 & 2,2162 & 1,27225 \\
\hline Olumsuz Söylemlerde Bulunma & 47 & 4,1351 & 1,03178 \\
\hline
\end{tabular}

Bu sonuçlar kamu kuruluşlarına güvenenlerin ve kamu spotlarında verilen iletileri etkili bulanların sosyal medyadaki olumlu söylemlere yönelik oranlarının kamu spotlarını etkisiz bulanların oranlarına göre oldukça yüksek olduğunu göstermektedir. \% 95 güven aralığında yapılan tek yönlü Anova testi sonucuna göre aralarındaki fark anlamlıydı $(\mathrm{F}=18,118 \mathrm{p}<0.05)$.

\section{Sonuç ve Değerlendirme}

Araştırma bulgularına göre salgın esnasında kamu kuruluşlarına güvenmeyenlerin ve kamu spotlarında verilen iletileri etkili bulmayanların duymuş oldukları hislerden dolayı olumsuz mesajları iletme ve olumsuz iletileri yorumlama, beğenme ve paylaşma oranlarının daha yüksek olduğu sonucuna ulaşılmıştır. Bu durumun salgın durumunda hissedilen duygularla (üzüntü, korku, öfke, endişe, kaygı) ve sosyal psikolojiyle alakalı olduğu söylenebilir. Böylesine olumsuz ve ciddi durumlar olumsuz etkiler yaratabilme potansiyeline sahiptir. Çünkü risk algısı arttıkça vatandaşların rasyonel düşünme ve davranma olasılı̆̆ı azalabilmektedir. Bu yüzden salgın döneminde halk üzerinde etkili olabilecek duygusal ve bilişsel algıların ayırt edilmesi gerekmektedir.

Sosyal medyanın artan popülaritesiyle beraber kamu kuruluşları salgına dair bilgilerin içeriğini oluşturan ve topluma yayan tek kuruluş olma özelliğini kaybedebilmektedir. Salgın esnasında kamu kuruluşlarından bilgi alınmamasının veya yetersiz bilgi alınmasının yaratacağı belirsizlik durumları sosyal medyada asılsız bilgilerin hızla yayılmasına ve böylece kamu kuruluşlarının güvenilirliği ve inandırıcllğ den olabilecektir. Araştırma verilerine göre kamu kuruluşlarını güvenilir bulmayan ve kamu spotlarında verilen bilgileri yetersiz ve etkisiz bulan katılımcıların sosyal medyadaki olumsuz söylemlere katılım oranları oldukça yüksek bulunmuştur. Bu durum kamu kuruluşlarına yönelik olumsuz söylemleri arttırmaktadır. 
Yapılan bir araştırma sonucuna göre izleyicilerin kamu spotlarına yönelik düşünceleri her ne kadar olumlu olsada bu kamu spotlarını izledikten sonra hissettikleri duyguların çoğunlukla olumsuz olduğu bulgusuna ulaşılmıştır (Dal Canbazoğlu, 2020, s. 356). Özellikle salgın nedeniyle zarar görme algısı arttıkça vatandaşların rasyonel düşünme ve davranma olasılığının azalabileceği söylenebilir. Bu nedenle halk sağlığına yönelik oluşturulmak istenilen algı için dijital medya ile ilgili faktörler ve haber çevrelerinin etkileri ayrı bir şekilde ele alınıp değerlendirilmelidir.

Afet durumları bir belirsizlik ortamı yaratmaktadır. Belirsizliğin üstünden gelmek için ise kamuoyuna etkili bir şekilde bilgi iletmek önemlidir. Ancak sadece bilgi vermek sorunların üstesinden gelinmesi için yeterli olmayabilir. Çünkü kamuoyu alınan bilgiden memnun olmadığı takdirde başta sosyal medya olmak üzere diğer alternatif kaynaklara yönelmektedir (Çelebi, 2020b, s.152) BBC News, New York Times, CNN International, RT, The Associated Press, The Independent ve The Guardian medya organlarının Corona virü ile ilgili dijital ortamlardaki haber içerikleri inceleyen Ulaş ve Yeşil (2020, s.939) Batı dijital medyasının Türkiye'nin imajını olumsuz şekilde etkileyebilecek olan manipülasyon ve dezenformasyon teknikleri ile birlikte yapılan algı yönetimi çabasını ortaya çıkarmıştır.

Halk verilen mesajları yeterli ve güvenilir bulduğunda salgın ortamının yarattığı duygusal ve bilişsel olumsuzluklara daha başarılı bir şekilde karşılık verebilecektir. Sosyal medyanın ise halkın davranışları üzerinde önemli bir etkisi olabilmektedir. Bu yüzden birbirleriyle tutarlı, inanılır, hızlı ve etkili iletişim stratejilerinin tasarlanması ve belirsizliğin üstesinden gelinmesi sosyal medyada olumsuz söylemleri engellemek için oldukça önemlidir. Böylece yanlış bilgilerin ve olumsuz söylemlerin yayılması önlenebilir.

Araştırma sonuçlarına göre kamu spotlarında kullanılan iletişim tekniklerinin etkinliğine yönelik olarak duygusal faktörler daha etkili olmakta ve dijital ortamlardaki etkileşimlere ve iletişim stratejilerinin etkinliğini belirlemede 1 lımlı bir rol oynamaktadır. Ancak kamu güveninin kazanılması için öncelikle kamu kuruluşlarının algılayıcı ve yetkin olduklarının kanıtlanması gerekmektedir.

Dijital ortamlarda öfke, stres, korku, kaygı veya güvensizlik duyguları oluşturabilecek olumsuz bilgileri, iddiaları ve söylentileri çürütmek ve risk seviyesini azaltmak için hızlı ve etkili bir müdahale sistemi gerekmektedir. $\mathrm{Bu}$ dönemde salgın dönemine yönelik olarak uzun vadeli ve kısa vadeli 
stratejiler izlemenin riskleri ve faydaları hakkında yeterli bilgi verilmelidir. Bu nedenle iletişim uygulayıcılarının dijital ortamlarda stratejik düşünme ve karar verme süreçlerine yönelik becerilerini geliştirmeleri gerekmektedir.

Dijital ortamlar aracılığıyla geleneksel medyada ve kamu spotlarında verilen bilgilerin yayılma hızları, kapsamları ve etkileri artabilmektedir. Dijital ortamların farklı platformlara ayrılmış yapıları nedeniyle bilgi paylaşımları daha fazla platformda gerçekleşmektedir. Bu nedenle bilgilerin daha derinlemesine analizini zorlaştırmaktadır. Tartışmalar, yorum, tepki, dayanışma ve protesto gibi eylemler her ne kadar birbirlerine bağlı gibi görünüyor olabilse de muazzam miktarda olan bu gayri resmi söylemleri kavramak oldukça zordur. Yine de katılımclların büyük bir çoğunluğu (\%83'ü) sosyal medya arac1lığıyla konuya dâhil olduklarını hissettiklerini ve böylece durumu yönetmek ve çözmek için iletişim kurmaya yönelik motive olduklarını belirtmiştir. Ancak iyi niyetten yoksun olmasa da kanıta dayalı olmayan olumsuz paylaşımların risk algısını artırdığı ve toplumsal kaygı yarattığı söylenebilir.

İletişim stratejileri tasarlanırken öfke, kaygı, korku, endişe vb. duyguların giderilmesine yönelik çabaların ön planda tutulduğunu göstermek oldukça önemlidir. Bu duyguların ise periyodik olarak ölçülmesi gerekmektedir. Duygusal destek veren mesajlar, empati kurulması ve toplumsal duyarlılığın dikkate alınması inanılırlığı, güveni ve kamu kuruluşlarına olan destekleyici davranışsal niyetleri arttırabilir.

Kamu spotları üzerine yapılan araştırmalar korku çekiciliği unsurlarının bireylerin algılarını olumlu yönde etkilediği yönündedir. Farkındalık yaratmak için korku unsurundan faydalanarak bireylerin algısı değiştirilebilmektedir (Fidan ve Yetiş, 2018, s.175). Diğer yandan, korku unsurunun kullanıldığı mesajlarda bireylerin bu olumsuz durumla nasıl baş edeceği, hangi toplumsal/kurumsal desteklerden faydalanacağı, kime nasıl başvuracağ 1 ve bu hizmetin bir maliyetinin olup olmadığına dair de bilgi vermelidir (Çobaner, 2018, s.821).

Toplumsal sorunlarda genellikle yetkililerden alınan bilgilerin yetersizliğinden şikâyet edilirken sosyal medya ortamlarında çok fazla bilgi vardır. Sosyal medyada katılımcılar kendi sorularına doğrudan bireysel cevaplar alabilmekte, karar alma süreçlerine katkı sağladıklarını düşünebilmekte, duygu ve davranışlarını ifade edebilmekte, başkalarının tepkilerini yorumlayabilmekte, tavsiyelerde bulunabilmektedirler. İletişim stratejilerinde etkililik beklentilerin karşılanmasına yönelik olarak anlayış ve anlam yaratmanın 
birleşmesine odaklanan genel bir süreçtir. Sosyal medyada güven oluşturmak ve güvenilirlik kazanmak için farklı durum ve koşullarda sebep-sonuç ilişkisinin araştırılması gerekmektedir.

\title{
Araştırmanın Sınırlılıkları ve Gelecek Araştırmalar İçin Öneriler
}

Gelecekte dijital/sanal iletişimin sosyal yaşam içinde çok önemli bir rol oynayacağı ve daha baskın olabileceği göz önünde bulundurularak araştırmanın örneklemini 20-30 yaş arasında olan, sosyal medyayı yoğun olarak kullanan ve yaşam tarzı olarak benimseyen İletişim fakültesi öğrencileri oluşturmuştur. Çünkü profesyonel yaşamlarında sosyal medyayla iç içe yaşama olasıllğı yüksek olan grubu temsil eden bu katılımcıların görüşü, gelecekte sosyal medya ile risk yönetiminin daha başarılı olması konusunda bize ışık tutabilecektir. Salgın durumu milyarlarca kişiyi etkilenmiş olmasına rağmen araştırma küçük bir örneklem grubu üzerinde yapılmıştır. Bu yüzden örneklem sayısının araştırmanın sonuçlarını genelleştirmek için sınırlı olduğu söylenebilir. Ayrıca örneklem seçimi belirlenirken hedef kitle ayrımı yapılmamıştır. Demografik özelliklere (yaş, eğitim düzeyi, cinsiyet vb.) göre her bir hedef kitle ayrımı farklı algılara sahip olabilir. Analizlere tüm iletişimsel eylemler dâhil edilmemiştir. Ayrıca araştırma tek bir ülkede yapılmıştır. Bu yüzden araştırma bulguları kültürel faktörlerden (bireyselcilik/kollektivizm vb.) etkilenmiş olabilir. Gelecek araştırmalarda daha büyük bir örneklemde iletişim stratejilerine yönelik bilgilendirici ve duygusal stratejilerin kamuoyunun tepkilerini nasıl etkilediği, her bir iletişim stratejinin etkinliğinin nasıl ortaya çıtığı ve bunların iletişimsel algılara ve davranışlara olan etkisi ayrı ayrı incelenebilir ve karşılaştırmalar yapılabilir. Ayrıca gelecek araştırmalarda medya ile ilgili faktörler ve haber çevrelerinin bireysel etkileri de değerlendirilebilir.

\section{EXTENDED ABSTRACT}

\section{A Research On The Effectiveness Of Public Spots For Covid-19 Pandemic Process}

\author{
Engin Çelebi - Seyfi Özgüzel \\ Cukurova University
}


It has become an important research subject on ensuring compliance with health rules utilizing public spots regarding the health risk caused by threatening public health. This study aims to determine the effect of communication techniques and reveal how this effect is related to emotional- and behavioral changes. For this purpose, it is aimed to test the mediating role of public spots in attitudes towards health rules. It aims to fill the gap in the literature and obtain theoretical and pragmatic inferences with the findings obtained from this study to reveal the effectiveness of public relations during the pandemic period, discussions in digital environments, social perception, and social adaptation.

Using open-ended questions and questionnaire technique, the research was conducted on 116 students studying at the Faculty of Communication. The data were collected digitally from the participants voluntarily, and it took one month to collect the data. Those included in the research were asked to describe the public spots they found effective and ineffective during the pandemic period. Thus, it is aimed to define and to categorize the communication strategies used in public media spots. Afterwards, participants were asked to answer a questionnaire measuring their attitudes and behaviors in digital environments. The study sample consists of people between the ages of 18-30 and who have received a university education. $46.6 \%(n=54)$ of the participants were women and $53.4 \%(n=62)$ were men.

At the beginning, the answers of the first research question that the participants wrote in the empty message box on the questionnaire were analyzed in order to determine which common features stand out in order to increase the effect of communication strategies in traditional and social media. According to the research findings, providing sufficient information for the effectiveness of public spots: expressing them briefly, explaining them in a simple language, being clear, consistent and believable are the primary features.

In addition, cognitive and emotional trust in public institutions and in the state, affects the trust in the messages given in the public spots. Approaches such as establishing empathy and taking into account reactions are determined as a feature specific to social media environment. In addition to the recommendations for measures, it was found that the participants were also interested in the messages about how the pandemic period occurred on social media. Participants showed different attitudes according to the effectiveness of communication strategies and behavioral intentions. 
Participants exchange ideas and support each other on social media on: how to take responsibility, how the pandemic emerges, whether it can be taken under control, who is responsible and guilty, what to do or not to do, or how to behave or not. In addition, empathy and using expressions for emotional as well as logical support were found effective when designing effective communication strategies. In order to determine communication strategies that may cause negative perceptions, the answers that the participants wrote in the empty message box on the questionnaire were analyzed and common features were revealed. Perceptions about not going beyond meeting the public's need for information and not taking responsibility came to the fore with the messages given for ineffective strategies. Such a situation may cause questioning the legitimacy of public institutions and the state. On the other hand, it was found that in social media generally posts with negative content about public health are made.

In digital environments are, dangerous, threatening, intimidating, harmful, risky expressions, worrying and increasing information conveyed, shared and is a perception of uncertainty created. It has been stated that emotional (not cognitive) and worrying expressions about what is frequently encountered in digital environments and these can cause immediate negative effects. This finding highlights the importance of involving the public in the process. Therefore, it is necessary to provide transparent information about what has been done to overcome the pandemic period, how it is worked and what should be done to prevent similar situations from repeating, in order to prevent unfounded rumors on social media. In addition, according to the results of the research, the rates of those who trust public institutions and find the messages given in public spots effective towards positive discourse on social media were found to be higher than the rates of those who found public spots ineffective.

Similarly, we see people who do not trust the message of health institutions in Turkey who also do not trust the public media spots. On the other hand, people who trust the message of health institutions in Turkey are also relying on public media spots in a similar way. For this reason, it can be argued that strengthening trust in healthcare institutions can also mean strengthening confidence in the effectiveness of public institutions.

According to the study's findings, it was concluded that those who do not trust public institutions during the pandemic and those who find the 
messages on public media ineffective are more likely, because of their feelings, to forward negative messages and like to share the negative messages with others. It can be said that this situation is a result of the emotions (sadness, fear, anger) felt in the pandemic situation and mass psychology. Such negative and serious situations can produce negative results. Because as risk perception increases, people's rational thinking and action options can diminish. Therefore, a distinction must be made between emotional and cognitive perceptions that could affect the public during the pandemic.

When designing communication strategies, anger, anxiety, etc., it is very important to show that efforts to eliminate emotions are prioritized. These feelings should be measured periodically. Emotional supportive messages, empathy, and social sensitivity consideration can increase credibility, trust, and supportive behavioral intentions to public institutions.

\section{Kaynakça / References}

Benoit, W.L. (1995). Accounts, excuses, and apologies: A theory of image restoration. State University of New York Press, Albany.

Borah, P. (2011). Conceptual issues in framing theory: A systematic examination of a decade's literature. Journal of Communication 61, 246-263.

Cheng, Y. ve Lee C-J. (2019). Online crisis communication in a post-truth Chinese society: Evidence from interdisciplinary literature. Public Relations Review 45, 110.

Choi, Y. ve Lin, Y-H. (2009). Consumer responses to mattel product recalls posted on online bulletin boards: Exploring two types of emotion. Journal of Public Relations Research 21:2, 198-207.

Coombs, W. T. (2014). Crisis management and communications. http://www.instituteforpr.org/crisis-management-communications/ adresinden erişilmiştir.

Coombs, W. T. (2019). Ongoing crisis communication: Planning, managing, and responding. Sage Publications, NY.

Çelebi, E. (2020a). Kurumsal halkla ilişkilerin etkinliğini ölçme: STK gönüllüleri üzerine bir araştırma. Selçuk İletişim 13 (1), 180-196.

Çelebi, E. (2020b). Sosyal medya ve krizde iletişim(sizlik): GSM operatörlerinin yaşadığı şebeke krizi üzerine bir araştırma. Akdeniz Üniversitesi Iletişim Fakültesi Dergisi 34, 141-158. DOI: 10.31123/akil.694122.

Çobaner, A.A. (2018). Bir sağlık iletişimi kampanyası geliştirmek, sağlık bakanlığı́'nın tütün karşıtı kampanyası üzerine bir analiz. Uluslararası Sosyal Araştırmalar Dergisi, 11(60), 808-823. 
Dal Canbazoglu, A. (2020). Türkiye'de covid-19 yeni koronavirüs hastallğı vakasının ortaya çıktı̆ı ve yayılmaya bașladığı ilk günlerde yayınlanan kamu spotu ve reklamların izleyici üzerindeki etkisi. Turkish Studies, 15(6), 351-389. https://dx.doi.org/10.7827/TurkishStudies.43904

Fidan, M. ve Yetiş, A. (2018). Sağllk iletişiminde algı: kamu spotları üzerine bir araştırma. Selçuk İletişim 11(2), 159-178.

Fraustino, J.D., Liu, B. ve Jin, Y. (2012). Social media use during disasters: a review of the knowledge base and gaps, final report to human factors/behavioral sciences division, science and technology directorate, U.S. Department of Homeland Security. College Park, MD: START.

Gudykunst, W. B. (2004). Bridging differences: effective intergroup communication. 4. bsm, Sage Publication, London.

Hofstede, G. (2011). Dimensionalizing cultures: The hofstede model in context. Online Readings in Psychology and Culture, Unit 2. Retrieved from http://scholarworks.gvsu.edu/orpc/vol2/iss1/8.

Jin, Y., Fraustino, J. D. ve Liu, B. F. (2016). The scared, the outraged, and the anxious: How crisis emotions, involvement, and demographics predict publics' conative coping. International Journal of Strategic Communication 10, 289-308.

Marynissen, H. ve Lauder, M. (2020). Stakeholder-focused communication strategy during crisis: A case study based on the Brussels Terror Attacks. International Journal of Business Communication, 57(2), 176-193.

National Science and Technology Council (2005). Grand challenges for disaster reduction: A report of the subcommittee on disaster reduction. Executive Office of the President, Washington, DC.

Paton, D. (2008). Risk communication and natural hazard mitigation: how trust influences its effectiveness. International Journal Of Global Environmental Issues, Vol $8(1-2), 2-16$.

Rodriǵuez, H., Quarantelli, E.L., Dynes, R.R., Anderson, W.A., Kennedy, P.J. ve Ressler, E. (2007). Handbook of disaster research. Springer, New York, NY.

Schultz, F., Utz, S. ve Göritz, A. (2011). Is the medium the message? Perceptions of and reactions to crisis communication via twitter, blogs and traditional media. Public Relations Review 37, 20-27.

Seeger, M.W., Sellnow, T.L. ve Ulmer, R.R. (1998). Communication, organization, and crisis. Annals of the International Communication Association, 21(1), 231-276.

Stieglitz, S., Bunker, D., Mirbabaie, M. ve Ehnis, C. (2018). Sense-making in social media during extreme events. Journal of Contingencies and Crisis Management 26, 4-15. 
Tanyıldızı, N. (2020). Covid-19 salgını sürecinde sağlık iletişiminde sosyal medya. İksad Publishing House, Ankara.

Turancı, E. (2018). Risk iletişimi açısından bilginin önemi ve bilgi okuryazarlığı. Illetişim Kuram ve Araştırma Dergisi, 47, 191-208.

Ulaş, M. ve Yeşil, A. (2020). Batı dijital medyasının Türkiye'ye yönelik algı manipülasyonu: Koronavirüs haberleri üzerine ampirik bir araştırma. Erciyes İletişim Dergisi, 7(2), 939-963.

Van der Meer, T. G. (2016). Public frame building: The role of source usage in times of crisis. Communication Research 45, 956-981.

Veil, S.R., Buehner, T. ve Palenchar, M. (2011). A work in-process literature review: Incorporating social media in risk and crisis communication. Journal of Contingencies and Crisis Management, 19(2), 110-122.

Witte, K. (1995). Generating effective risk messages: How scary should your risk communication be?. Communication Yearbook, 18(1), 229-254.

World Health Organization. E.T. 08.11.2020 https://www.who.int/emergencies/riskcommunications

Zhao, X., Zhan, M.M. ve Liu, B.F. (2019). Understanding motivated publics during disasters: Examining message functions, frames, and styles of social media influentials and followers. J Contingencies and Crisis Management 27, 387-399.

\section{Kaynakça Bilgisi / Citation Information}

Çelebi, E. ve Özgüzel, S. (2021). Covid-19 pandemi sürecine yönelik kamu spotlarının etkinliği üzerine bir araştırma. OPUS-Uluslararası Toplum Araştırmaları Dergisi, 17(Pandemi Özel Sayısı), 3348-3469. DOI: 10.26466/opus. 810640 